\title{
Residual colonization by vaccine serotypes in rural South Africa four years following initiation of pneumococcal conjugate vaccine immunization
}

\author{
Shabir A. Madhi, ${ }^{1,2}$ Susan A. Nzenze, ${ }^{1,2}$ Marta C. Nunes,,${ }^{1,2}$ Lilian Chinyanganya, ${ }^{1,2}$ Nadia \\ van Niekerk, ${ }^{1,2}$ Kathleen Kahn, ${ }^{3,4,5}$ Rhine Twine, ${ }^{3}$ Linda de Gouveia, ${ }^{6}$ Anne von Gottberg, ${ }^{6}$ \\ Tinevimbo Shiri $1,2,7$
}

${ }^{1}$ Department of Science and Technology/National Research Foundation: Vaccine Preventable Diseases, University of the Witwatersrand, Johannesburg, South Africa; ${ }^{2}$ Medical Research Council: Respiratory and Meningeal Pathogens Research Unit, School of Pathology, Faculty of Health Sciences University of the Witwatersrand, Johannesburg, South Africa; ${ }^{3} \mathrm{MRC} / \mathrm{Wits}$ Rural Public Health and Health Transitions Research Unit, School of Public Health, Faculty of Health Sciences, University of the Witwatersrand, Johannesburg, South Africa; ${ }^{4}$ Centre for Global Health Research, Umeå University, Umeå, Sweden; ${ }^{5}$ INDEPTH Network, Accra, Ghana; ${ }^{6}$ Centre for Respiratory Diseases and Meningitis, National Institute for Communicable Diseases, National Health Laboratory Service, Johannesburg, South Africa; ${ }^{7}$ Liverpool School of Tropical Medicine, Liverpool, United Kingdom

Corresponding author:

Shabir A Madhi

Respiratory and Meningeal Pathogens Research Unit, Chris Hani Road; Chris HaniBaragwanath Hospital, New Nurses Residence, $11^{\text {th }}$ Floor West Wing 2013 Bertsham, South Africa E-mail: madhis@rmpru.co.za; Telephone: +27119834266 
Funding: Funding for this project was provided by the South Africa Department of Science and Technology and the National Research Foundation (South African Research Chair Initiative in Vaccine Preventable Diseases) and the Respiratory and Meningeal Pathogens Research Unit of the Medical Research Council of South Africa.

Declaration of interest: S A Madhi received research funding and honoraria from Pfizer and GlaxoSmithKline. M C Nunes received honoraria from Pfizer. A von Gottberg received research funding from Pfizer. The authors have no other relevant affiliations or financial involvement with any organization or entity with a financial interest in or financial conflict with the subject matter or materials discussed in the manuscript apart from those disclosed.

Reviewer Disclosures: A reviewer on this manuscript has disclosed grant funding and consulting fees from Pfizer and Merck. All other peer reviewers on this manuscript have no relevant financial or other relationships to disclose.

Author Contributions: S A Madhi and S A Nzenze designed the trial and study protocol. S A Nzenze, L Chinyanganya, K Kahn, R Twine, oversaw the clinical data collection and clinical data management. N van Niekerk, L de Gouveia, A von Gottberg were responsible for laboratory analyses. S A Madhi, SA Nzenze and T Shiri conducted the statistical analysis. S A Madhi wrote the first draft of the paper with input from S A Nzenze, M C Nunes and T Shiri. All authors inputted to subsequent drafts, read and approved the final version of the report. 


\begin{abstract}
Background: We evaluated pneumococcal colonization in children and adults between the time of 7-valent pneumococcal conjugate vaccine $(\mathrm{PCV})$ introduction in the immunization program in April 2009 to two years after transitioning to 13-valent PCV in 2011.

Methods: Community-based pneumococcal carriage surveillance was undertaken between May-November 2013 (Period-3; n=1884), with similar surveys in 2009 (Period-1, n=2010) and 2011 (Period-2; n=3659). Households with children below two years had a similar probability of being sampled in all surveys. Nasopharyngeal swabs were processed using standard methods and serotyped by Quellung.
\end{abstract}

Results: In children $>9-59$ months of age, overall pneumococcal colonization prevalence declined from $81.8 \%$ in Period- 1 to $65.0 \%$ in Period-3 ( $\mathrm{p}<0.001$ ). Reductions of $70 \%$ (95\%CI: $60 \%-77 \% ; 41.2 \%$ vs. $13.6 \%$ ) in PCV7-serotypes colonization and $66 \%$ (95\%CI:48\%-78\%; 15.3\% vs. 4.4\%) for the six additional PCV-serotypes in PCV13 (PCV13add6VT) were observed. There was, however, high residual prevalence of colonization by PCV7-serotypes $19 \mathrm{~F}$ (14.9\% vs. $6.3 \%$ ) and $23 \mathrm{~F}$ (8.5\% vs. $4.1 \%$ ), despite reduction of $57 \%$ (95\% CI:35\%-80\%) and 52\% (95\%CI:21\%-83\%), respectively. Among individuals $>12$ years of age, there was $61 \%(95 \% \mathrm{CI}: 18 \%-82 \%)$ reduction in PCV7-serotype colonization $(3.1 \%$ vs. 1.3\%; ) and 75\% (95\%CI: 11\%-93\%) decrease for PCV13-add6VT (2.1\% vs. $0.6 \%)$ between Period-1 and Period-3.

Conclusions: The residual prevalence of serotypes $19 \mathrm{~F}$ and $23 \mathrm{~F}$ in PCV-immunized and unvaccinated age-groups, four years after introducing PCV in the South African public immunization program, suggests ongoing community transmission and transient vaccine effects. 
Keywords: Streptococcus pneumoniae, colonization, carriage, pneumococcal conjugate vaccine, serotypes 


\section{Introduction}

Pneumococcal conjugate vaccine (PCV) immunization of children reduces their risk of Streptococcus pneumoniae (pneumococcus) vaccine-serotype nasopharyngeal acquisition and disease ${ }^{1,2}$. Since young children are the major source of transmission of pneumococci in the community ${ }^{3,4}$, childhood PCV immunization has also reduced the prevalence of vaccineserotype colonization among unvaccinated age groups ${ }^{2,5-7}$. Although there has been near elimination of PCV-serotype colonization and invasive disease in some high-income countries following childhood PCV immunization ${ }^{8,9}$, there are limited data from low-middle income countries ${ }^{10,11}$, including from settings with high prevalence of HIV infection.

Monitoring the prevalence of pneumococcal vaccine-serotype colonization, a pre-requisite for developing pneumococcal disease ${ }^{12}$, is a potential metric for assessing the indirect effect of childhood PCV-immunization against vaccine-serotype pneumococcal disease in older, nonimmunized age-groups ${ }^{1}$.

The 7-valent PCV (PCV7) was introduced in the South African public immunization program in April 2009, using a 6, 14 and 40 weeks of age dosing schedule; with no catch-up campaign of older children. In May 2011, the immunization program transitioned to 13-valent PCV (PCV13), with a limited catch-up campaign for children less than 36 months (m.) of age and in those $36-71 \mathrm{~m}$. with underlying medical conditions. We previously reported, in a rural setting with high HIV prevalence, within two years of PCV7 introduction and when PCV coverage in children was modest (52\%), a 50-64\% reduction in PCV7-serotype colonization prevalence in age-groups targeted and not targeted for PCV immunization ${ }^{13}$.

The aim of this study was to evaluate the prevalence of vaccine-serotype and non-vaccine serotype (NVT) pneumococcal nasopharyngeal colonization in children $(>9-59 \mathrm{~m}$. and $60-$ $144 \mathrm{~m}$. age) and household members older than 12 years (y.) of age in a rural African setting, 
two years following transitioning from PCV7 to PCV13 in the infant public immunization program.

\subsection{Methods}

2.1 Study population and study methods

This community-based study was undertaken in Agincourt sub-district, a health-socio demographic surveillance site (HDSS) in Mpumalanga province, South Africa. The pneumococcal colonization survey performed from May to November 2013 (Period-3) was preceded by two earlier cross-sectional surveys approximating the same calendar months in 2009 (Period-1) and 2011 (Period-2) as described ${ }^{13}$. Aside from children $<9$ m. not being enrolled during Period-1, the sampling strategy and methodology was similar across the three surveillance periods ${ }^{13}$. Briefly, households with children aged $\leq 24 \mathrm{~m}$. were identified from the HDSS database as potential participants. A random list of villages was generated and households with children less than two years old were selected until the required sample size was achieved. A total of 9, 26 and 19 villages were selected in 2009, 2011 and 2013, respectively. All 9 villages included in 2009 were also included in 2011, and 16 villages selected in 2011 were also included in sampling during to 2013. Households were included if, in addition to the listed child, there was at least one individual $>12 y$. who agreed to studyparticipation. Although the same household could have been randomly selected in any of the three sampling periods, the same child would generally have contributed to an older child age-group stratum.

A questionnaire was administered at the time of nasopharyngeal swab collection. HIV status was based on self-reporting in the first two study-periods. In Period-3, HIV testing following counselling was offered to individuals older than $18 \mathrm{y}$. HIV testing was not undertaken in the younger age-group due to an anticipated low HIV prevalence in individuals aged $<18 \mathrm{y}$, and 
consequently we relied on self-reporting by parents/care-givers for HIV-infection status for these individuals. This was premised on the successful roll-out of the mother-to-child HIV prevention program between 2008 and 2011, following which the mother-to-child HIV transmission rates declined from $9.6 \%$ to $2.3 \% .^{14}$

The sample collection and laboratory testing methods for culture of bacteria, including Streptococcus pneumoniae, Haemophilus influenzae and Staphylococcus aureus, were as previously reported ${ }^{13,15}$. Briefly, nasopharyngeal swabs were performed in all subjects using an aluminum shafted, Dacron swab (MW and E, Medical Wire and Equipment Co. Ltd., Corsham, Wiltshire, England), in addition to which an oropharyngeal swab was collected from those older than $12 \mathrm{y}$. Samples were processed at the Centre for Respiratory Diseases and Meningitis (CRDM) at the National Institute for Communicable Diseases, South Africa, by routine microbiological methodologies. Serotyping was undertaken by the Quellung method using factor and serotype-specific antisera (Statens Serum Institute, Copenhagen, Denmark). Presumptive pneumococcal presenting no phenotypically detectable capsule were categorized as non-typeable, once pneumococcal identification was confirmed with lytA PCR. Where $>1$ distinct morphological colony type was present, each colony was serotyped. Serotypes $6 \mathrm{~A}, 6 \mathrm{~B}, 6 \mathrm{C}$ and $6 \mathrm{D}$ were distinguished only using the relevant antisera and without any additional molecular typing.

\subsection{Sample size calculation}

The sample size for Period- 3 was based on providing $80 \%$ power to detect a $30 \%$ reduction in PCV13-no-PCV7 serotypes, i.e. PCV13-additional six serotypes (PCV13-add6VT) colonization among individuals $>12 \mathrm{y}$. age (referred to as "adults" henceforth) relative to the $1.1 \%$ prevalence documented in 2011. This required enrolment of 900 adults. We estimated that to enroll 900 adults, we would require visiting at least 450 households with at least one 
child aged $<24 \mathrm{~m}$. Based on PCV13-add6VT colonization prevalence of $15.2 \%$ in 2011 among children aged $<24 \mathrm{~m}$., the enrolled number of children $<24 \mathrm{~m}$. age $(\mathrm{n}=434)$ would provide $80 \%$ power to detect at least a $40 \%$ reduction in prevalence of PCV13-add6VT colonization in this age-group.

\subsection{Statistical analysis}

Multiple, simultaneous colonization by different serotypes in the same individual were considered as independent events when measuring the prevalence of colonization if they differed in stratification into PCV7-serotypes (4, 6B, 9V, 14, 18C, 19F and 23F), PCV13add6VT $(1,3,5,6 \mathrm{~A}, 7 \mathrm{~F}$ and 19A) or non-vaccine serotypes (i.e. any other pneumococcal serotype including non-typeable isolates). Comparison of the prevalence of serotype-specific pneumococcal colonization between Period-3 and Period-1 were calculated using $\chi^{2}$ or Fisher's exact test where appropriate. Serotype-specific analysis was not adjusted for any potential confounders. Log-binomial regression models with the log link function were used to estimate the risk ratios for pneumococcal carriage in Period-3 compared to Period-1, adjusting for potential confounding factors such as age, gender, fuel used for cooking in the household, presence of a child attending day care and household structure. Statistical analyses were conducted using SAS version 9.4 (SAS Institute, Inc., NC).

\subsection{Ethics}

The study was approved by the Human Research Ethics Committee (Medical, M130461) at the University of the Witwatersrand and the Mpumalanga Department of Health Ethics Committee. Informed written consent was obtained from participants $\geq 18 \mathrm{y}$. old, and parental/guardian consent was obtained for younger participants. In addition, those aged 8$17 \mathrm{y}$. provided verbal assent for study participation.

3.0 Results 
We enrolled 2010 (from 577 households), 3659 (1079 households) and 1884 (563 households) individuals in 2009 (Period-1), 2011 (Period-2) and 2013 (Period-3), respectively; as detailed in Table 1. Differences in demographic characteristics in Period-3 compared to Period-1 included fewer individuals per household (mean 5.6 vs. 8.8; $<<0.001$ ), including fewer children $\leq 5 \mathrm{y}$. age (mean 1.5 vs. $1.8 ; \mathrm{p}=0.014$ ). Also, households were less likely to use coal/wood for cooking ( $43.8 \%$ vs. $69.9 \%$ ), and conversely more likely to use electricity ( $55.8 \%$ vs. $28.2 \%$; $<<0.001)$; Table 1 . Children were less likely to ever have been breastfed in Period-3 (82.5\%) compared to Period-1 (92.0\%; $<<0.001)$; albeit similar in the 12-24m. age-group ( $81.8 \%$ vs. $85.7 \%$ ). Children were less likely to be on antibiotics at time of sampling in Period-3 (1.5\%) than Period-1 (7.7\%; $p=0.002)$. The prevalence of parentalreported HIV-positivity in their children was comparable across the study periods (3.0 to 3.2\%). None of the children were immunized in Period-1. In Period-3, 65.2\% of children 3$9 \mathrm{~m}$. age received at least two PCV doses; and $82.2 \%$ of those $>9-24 \mathrm{~m}$. received at least three PCV doses, as did $49.8 \%$ in the $24-59 \mathrm{~m}$. age-group; Table 1 . None of the older children (60$144 \mathrm{~m}$.) were immunized with PCV in any of the three periods.

Among the adults (>12y. age), the mean age was lower in Period-3 (31.8y.) than Period-1 (33.3y.; $p=0.040$ ), albeit unlikely to be of clinical significance. The prevalence of selfreported HIV-positivity was higher in Period-3 (22.0\%) than Period-1 (7.9\%; $<<0.001)$, including those $>18 \mathrm{y}$. age ( $8.3 \%$ vs. $23.4 \%)$. Among adults $>18 \mathrm{y}$. old who consented for HIV testing in Period-3 ( $\mathrm{n}=456)$, the HIV-positivity prevalence was $20.2 \%(\mathrm{n}=92)$; including being positive in $100 \%(\mathrm{n}=50)$ of those who self-reported to be HIV-infected, and positive in a further 36 individuals who self-reported to be HIV-uninfected. Of the self-reported HIVinfected individuals, $55.3 \%$ and $70.8 \%$ were on antiretroviral therapy in Period-1 and Period3 , respectively. Generally, there was a low prevalence of smoking ( 1.7 to $2.2 \%$ ), sniffing of tobacco $(2.0$ to $2.7 \%)$ or alcohol use $(6.4 \%$ to $10.5 \%)$ across the study-periods. A higher 
percentage of individuals in Period-3 (19.3\%) than Period-1 (13.9\%; $\mathrm{p}=0.002)$ had an underlying chronic medical illness, and 0.9 to $1.0 \%$ were on treatment for tuberculosis; Table 1.

3.1 Overall prevalence of pneumococcal colonization

Across all age-groups, the prevalence of overall pneumococcal colonization was lower in Period-3 (35.8\%) than Period-1 (42.4\%; adjusted risk ratio [aRR]: 0.81, p <0.001); Table 2 and Figure 1. This included lower prevalence in Period-3 compared to Period-1 in children aged $>9$ m-59m. $(65.0 \%$ vs. $81.8 \%$; aRR: $0.81, p<0.001)$ who were eligible to have been vaccinated by Period-3, as well as in the PCV-naïve $60-144 \mathrm{~m}$. age-group (51.8\% vs. $60.0 \%$; aRR: $0.82, \mathrm{p}=0.03)$; Table 2 .

In individuals $>12 y$. age, overall prevalence of pneumococcal colonization did not differ between Period-3 (10.6\%) and Period-1 (11.3\%); although a significant reduction was observed in the $>12-18 y$ age group $(22.8 \%$ vs. $15.3 \%$; aRR: $0.58, p=0.04)$; Table 2 . This was in contrast to our previous observation of reduction in overall pneumococcal colonization in the $>12$ y. age-group between Period-1 (11.3\%) and Period-2 (6.8\%; aRR: 0.53); including in the $>12-18 y$. (22.8\% vs. $12.3 \%$; aRR: 0.51$)$ and $>18-45 y$. (10.7\% vs. $5.8 \%$; aRR:0.44) agegroups.

\subsection{Prevalence of PCV7-serotype colonization}

Overall prevalence of PCV7-serotype colonization declined by $66.0 \%$ (95\% CI: $56 \%$ - 73\%) between Period-1 (18.3\%) and Period-3 (6.8\%); including further reduction from Period-2 (11.4\%) to Period-3 (aRR: 0.58, $<<0.001$ ). The lower prevalence of PCV7-serotype colonization in Period-3 (13.6\%) compared to Period-1 (41.2\%; aRR: 0.30, p<0.001) among children $>9-59 \mathrm{~m}$. age, was evident in the $>9-23 \mathrm{~m}$. (13.4\% vs. $45.1 \%$; aRR: $0.26, \mathrm{p}<0.001)$ and $24-59 \mathrm{~m}$. (14.7\% vs. $35.5 \%$; aRR: $0.37, \mathrm{p}<0.001)$ age-groups. There was also a $41 \%(95 \%$ 
CI: $2 \%-64 \%)$ reduction of PCV7-serotyope colonization in Period-3 (10\%) compared Period-1 (19.0\%) in the PCV-naïve 60-144m. age-group.

There was $61 \%$ (95\% CI: $18 \%$ - 82\%) lower prevalence of PCV7-serotype colonization in the $>12 y$. age-group in Period-3 (1.3\%) compared to Period-1 (3.1\%); although no further significant decline was observed between Period-2 (1.2\%) and Period-3 (aRR: 0.86, p=0.73). Reductions in PCV7-colonization from Period-1 to Period-3 were detected in the 18-45y. (3.0\% vs. $1.0 \%$; aRR: $0.21, \mathrm{p}=0.02)$ age-group, whilst the reduction in the $12-18 \mathrm{y}$. age-group (5.7\% vs. $3.4 \%$; aRR: $0.64, \mathrm{p}=0.42)$ was not significant; Table 2 .

4.3 Prevalence of PCV13 additional-6 serotypes colonization

Overall and across specific age-groups, the prevalence of PCV13-add6VT colonization was similar in Period-1 and Period-2; Table 2. Within two-years of transitioning from PCV7 to PCV13, the overall prevalence of PCV13-add6VT colonization declined by $66 \%$ (95\% CI: 51\% - 77\%) (Period-1 7.9\% vs. Period-3 2.8\%). The reduction in PCV13-add6VT colonization was evident across all age-groups (albeit not analyzable for $>45 \mathrm{y}$. age). In those $>9-59 \mathrm{~m}$. age, PCV13-add6VT colonization decreased by 66\% (95\% CI: 48\%-78\%), from $15.3 \%$ in Period- 1 to $4.4 \%$ in Period-3; including reductions in the $>9-23 \mathrm{~m}$. (72\% $(95 \% \mathrm{CI}$ : 50\% - 84\%)) and 24-59m. (60\% (95\% CI: 24\% - 79\%)) age-groups. A 59\% (95\% CI: 19\% 80\%) reduction in PCV13-add6VT colonization was also observed in Period-3 (5.6\%) compared to Period-1 (11.0\%) in the PCV-naïve 60-144m. age-group.

Likewise, the prevalence of PCV13-add6VT colonization was 75\% (95\% CI: $11 \%$ - 93\%) lower in the $>12 y$. age-group in Period-3 (0.6\%) compared to Period-1 (2.1\%); including $89 \%$ (95\% CI: $4 \%-99 \%)$ reduction in the $12-18$ y. (1.1\% vs. $5.7 \%)$ and $73 \%(95 \%$ CI: $12 \%-$ $91 \%)$ decline in the $18-45 y$. age-group (0.7\% vs. 1.9\%); Figure 1 and Table 2.

3.4 Prevalence of non-PCV13 serotype colonization 
Although the overall prevalence of NVT colonization was similar between Period-1 (18.4\%) and Period-2 (19.3\%; aRR: 1.06, $\mathrm{p}=0.44)$, it increased to $26.8 \%$ by Period-3 (aRR: 1.49 , $\mathrm{p}<0.001)$. The increase in NVT colonization in Period-3 (47.8\%) compared to Period-1 (29.5\%, aRR: $1.84, \mathrm{p}<0.001)$ was evident for children $>9-59 \mathrm{~m}$. age, including $2.06(95 \% \mathrm{CI}$ : $1.63-2.61)$ and 1.60 (95\% CI: $1.24-2.07)$ adjusted-fold increases in the $>9-23 \mathrm{~m} .(48.5 \%$ vs. $27.1 \%,<0.001)$ and $24-59 \mathrm{~m} .(49 \%$ vs. $33 \%, \mathrm{p}=0.003)$ age-groups, respectively. There was no change in NVT colonization in the $60-144 \mathrm{~m}$. age-group (33.2\% in Period- 1 vs. $37.2 \%$ in Period-3, $\mathrm{p}=0.78)$.

Among individuals $>12 \mathrm{y}$. age although there was an initial decrease in NVT colonization between Period-1 (6.6\%) and Period-2 (4.7\%; aRR: 0.57, $\mathrm{p}=0.004)$; there was a $113 \%(95 \%$ CI: $47 \%-212 \%)$ increase in NVT colonization by Period-3 (8.9\%) compared to Period-2. Although the prevalence of NVT in Period-3 was slightly higher than in Period-1, this was not significant (aRR: 1.18, $\mathrm{p}=0.37$ ); Table 2 .

\subsection{Serotype-specific colonization by age-group}

Reductions in prevalence of PCV13-serotype colonization were observed for most serotypes with $\geq 1.5 \%$ prevalence in Period- 1 (except $9 \mathrm{~V}$ ) in the $>9-59 \mathrm{~m}$. age-group, with similar observations when stratified by $>9-23 \mathrm{~m}$. and $24-59 \mathrm{~m}$. age; Table 3 . In the $>9-59 \mathrm{~m}$. agegroup, this included reduction in colonization prevalence between Period-1 and Period-3 for serotypes 6B (84.6\%, p<0.001), $14(95.4 \%, \mathrm{p}<0.001), 18 \mathrm{C}(86.7 \%, \mathrm{p}=0.007), 19 \mathrm{~F}(57.7 \%$, $\mathrm{p}<0.001), 23 \mathrm{~F}(51.8 \% ; \mathrm{p}=0.001), 6 \mathrm{~A}(83.1 \% ; \mathrm{p}<0.001)$ and 19A $(56.5 \% ; \mathrm{p}=0.007)$; Table 3 . There, however, remained a prominent residual colonization prevalence in Period-3 of PCV7 (13.6\%) and PCV13-add6VT (4.4\%), with the dominant vaccine-serotypes including 19F $(6.3 \%), 23 \mathrm{~F}(4.1 \%), 19 \mathrm{~A}(2.0 \%), 6 \mathrm{~B}(1.7 \%)$ and $6 \mathrm{~A}(1.5 \%)$, which were also the top-five PCV13 colonizing serotypes in Period-1 (14.9\%, 8.5\%, 4.6\%, 10.1\% and 8.9\%, respectively); 
Table 3. Furthermore, significant increases in NVT colonization between Period-1 and Period-3 in the $>9-59 \mathrm{~m}$. age-group included serotypes $15 \mathrm{~A}(0.6 \%$ vs. $2.4 \%$; $\mathrm{p}=0.006), 16 \mathrm{~F}$ (0.7\% vs. $5.6 \% ; p<0.001), 21(0.1 \%$ vs. $1.7 \% ; p=0.003), 34(2.7 \%$ vs. $6.8 \% ; p<0.001)$ and 35B (0.6\% vs. $4.7 \% ; \mathrm{p}<0.001)$.

In the PCV-naïve 60-144m. age-group, although significant reductions were observed for colonization by vaccine-serotypes $4(100 \% ; \mathrm{p}=0.007)$ and $6 \mathrm{~A}(91.1 \%, \mathrm{p}=0.003)$, there were no reductions between Period-1 and Period-3 for serotypes 19F (4.2\% vs. 4.1\%), 23F (4.5\% vs. $3.2 \%)$ and $3(3.9 \%$ vs $3.6 \%)$; Table 3 . The only NVT to show a significant increase in the 60-144m. age-group in Period-3 compared to Period-1 was 35B (4.8\% vs $0.3 \%$; $\mathrm{p}<0.001)$.

In the $>12 y$. age-group, the prevalence of PCV13-serotype colonization in Period-1 was $<1 \%$ for all serotypes (except serotype 3), and although trending to lower prevalence in Period-3, the differences were not statistically significant. For serotype 3 , the colonization prevalence declined to $0.2 \%$ in Period-3 compared to $1.0 \%$ in Period- $1(p=0.030)$. Significant increases in NVT colonization in Period-3 compared to Period- 1 in the $>12 y$. age-group were evident for serotypes $8(0.6 \%$ vs. $0 \%$; $\mathrm{p}=0.01)$ and $35 \mathrm{~B}(1.4 \%$ vs. $0 \%$; $\mathrm{p}<0.001)$; Table 3 .

\subsection{Association of HIV infection and pneumococcal colonization}

There were very few children $<12 y$. age in Period-3 $(n=15)$ that were HIV-infected based on self-reporting, hence, limiting any comparisons on whether differences in colonization prevalence existed by HIV-status. For individuals $>18$ y. age with self-reported HIV-status, there was a higher prevalence of PCV7-serotype colonization in those living with $(2.5 \%)$ compared to those without $\operatorname{HIV}(0.4 \% ; \mathrm{p}=0.010)$, albeit not evident when limited to analyzing those in whom HIV testing was done; Table 4. Also, there were no differences for overall, PCV13-add6VT or NVT colonization in adults living with and without HIV; Table 4.

\section{Discussion}


In this study, undertaken in a rural, low-income African setting with high prevalence of adults living with HIV, immunization of children with a two dose primary series ( 6 and 14 weeks of age) and a booster dose at 40 weeks of age, was associated with rapid decline in colonization by PCV7 and PCV13-add6VT serotypes in the age-groups targeted for vaccination as well as in older-children (60-144m.) and among adolescents/adults (>12y.) who were naïve for any pneumococcal vaccination. Notably, the reductions in PCV7 and PCV13-add6VT colonization in the vaccine-naïve groups $(>60 \mathrm{~m}$. age) occurred within two years of introduction of PCV7 and PCV13, respectively, into the public immunization program. Additionally, although NVT colonization increased by almost $50 \%$, complete replacement of carriage by NVT was not yet realized in this community.

Sizeable vaccine indirect effects were observed, with the percentage reduction in PCV7 and PCV13-add6VT colonization in Period-3 compared to Period-1 in the $60-144 \mathrm{~m}$. been $41 \%$ and $59 \%$, respectively; and $61 \%$ and $75 \%$, respectively in the $>12 y$. age-group. These pointestimates (albeit overlap of the 95\%CI) were lower than the reduction in PCV7 (70\%) and PCV13-ad6 (66\%) observed in the $>9-59 \mathrm{~m}$. age-group that were eligible for PCVimmunization. Nonetheless, despite up-to-date vaccine coverage of $82.2 \%$ in the $>9-23 \mathrm{~m}$. age-group in Period-3, there was residual colonization by PCV7-serotypes of $13 \%$ and PCV13-serotypes of $18 \%$ in these children and in the combined $>9-59 \mathrm{~m}$. age-group. The prevalence of PCV7-serotypes being above $10 \%$ shows that there is still significant ongoing transmission of these serotypes in the community. These findings are in contrast to observations in industrialized countries where within a similar period post-PCV7 introduction, the prevalence of vaccine-serotype colonization among children $<2$ years old in Boston, USA, was around 2\% ${ }^{16}$ and $3.6 \%$ in England ${ }^{6}$. The absence of an initial catch-up campaign at vaccine introduction may have left a reservoir of PCV-serotypes among 
unvaccinated older children, resulting in continued transmission of these types in the community.

Similarly, high residual prevalence of vaccine-serotype colonization in age-groups targeted for vaccination, as well as in unvaccinated age-groups have been observed from other subSaharan African countries, including in the presence of using different dosing schedules with or without catch-up campaigns. In The Gambia PCV7-serotype colonization prevalence among children have been observed in villages where there was no catch-up campaign (13.6\% among children aged 2.5 to 5 years) ${ }^{17}$ and with PCV13-serotypes at five years after PCV13 introduction (11.4\% among 6 to 12 months old infants) using a three dose primary series and no booster dose $(3+0 \text { schedule })^{18}$. In rural Malawi, the reduction in PCV13serotype colonization in children 1-4years eligible to have been immunized with PCV13, declined by $63 \%$ (28.2\% vs. $17.9 \%)$; and was also $67 \%$ lower in women living without HIV (6.6\% vs. $2.4 \%)$ within four years of introducing PCV13 (3+0 schedule) into the childhood immunization program ${ }^{19}$.

The impact of catch-up campaigns in protection of at risk children against invasive pneumococcal disease is widely accepted ${ }^{20}$, however, its effect on carriage has not been well described. In Kilifi, Kenya, where 10-valent PCV was introduced as a three-dose primary series coupled with a catch-up campaign through to five years of age, there was also only partial reduction, i.e. 74\% (95\%CI: 66-80) in PCV10-serotype colonization from the prevaccine era $(33.8 \%$ vs. $8.8 \%))$ through to five years after introduction ${ }^{21}$.

Although limited by sample size, in our study for those PCV13-serotypes with $>1 \%$ colonization prevalence among the $>9-59 \mathrm{~m}$. age-group in Period-1, the percentage reduction in colonization by Period-3 varied from 95\% (14), 83-87\% (6A, 6B and 18C), to more modest $38-58 \%(3,23 \mathrm{~F}, 19 \mathrm{~A}, 19 \mathrm{~F}$ and $9 \mathrm{~V})$; among the latter group, serotypes $19 \mathrm{~F}$ and $23 \mathrm{~F}$ 
were the most common colonizing serotypes in Period-1. The high residual PCV13-serotype colonization was dominated by these two serotypes, both of which are included in PCV7 that was introduced into the immunization program four years before sampling was undertaken in Period-3. Moreover, there was no change in prevalence between Period-1 and Period-3 for serotype $19 \mathrm{~F}(4.2 \%$ vs. $4.4 \%)$ and $23 \mathrm{~F}(4.5 \%$ vs. $3.2 \%)$ colonization in the $60-144 \mathrm{~m}$. agegroup. The reasons for the differential impact of PCV immunization on colonization by different serotypes are still hypothetical.

In the older age-groups $(>12 \mathrm{y}$.$) , contrary to the scenario in children, declines in PCV7-$ serotype colonization were detected from Period-1 (3.1\%) to Period-2 (1.2\%) but no further reductions were detected by Period-3 (1.3\%), suggesting that this indirect effect of childhood vaccination might have reached a plateau state two years after PCV7 introduction despite increase in vaccination coverage including in a wider age range. A dynamic transmission model using data from Blantyre, Malawi, suggested that the high residual vaccine serotype colonization levels at seven years post-PCV13 introduction was mainly due to age-related characteristics of the local force of infection ${ }^{22}$. Further, the model at 10 years post-PCV13 introduction, estimated that there would be approximately $75 \%$ reduction in PCV13-serotype colonization across all age-groups ${ }^{22}$. In our setting it could be that PCV coverage is still suboptimal for complete indirect effects to materialize in adults, leading to a lag in time between the effects observed in children. Another explanation could be that there exists a reservoir of unvaccinated age groups contributing to the ongoing transmission of some the PCV7-serotypes in settings such as ours, as opposed to in high-income countries where children 1-4 years of age are considered the main source of pneumococcal transmission. ${ }^{23} \mathrm{~A}$ reduction in colonization by PCV13-add6VT was, however, detected in the $>12 \mathrm{y}$. age-groups between Period-2 and Period-3. 
Of the individual PCV serotypes, 3 was the only serotype with a lower colonization prevalence in Period-3 compared to Period-1 in the $>12 y$. age-group. Interesting, no significant temporal changes were noted for serotype 3 colonization among the $>9-59 \mathrm{~m}$. and $60-144 \mathrm{~m}$. age-groups, and the highest prevalence was in the $60-144 \mathrm{~m}$. group. These results suggest that the dynamics of colonization and transmission might differ for serotype 3 , and that the reduction in older individuals may be due to temporal changes rather than indirect effects of childhood vaccination. Previously, we have reported that adults living with HIV had higher prevalence of PCV-serotype colonization, including that of serotype 3 when compared to HIV-uninfected individuals ${ }^{13}$, and this was corroborated by data from Malawi and Uganda ${ }^{24,25}$. In the current analysis probably due to the small number of adults confirmed to be HIV-infected no differences were detected.

In the $>9-144 \mathrm{~m}$. age-group there were gradual reductions in overall pneumococcal colonization during the three sampling Periods despite significant increases in NVT colonization. In the $>12 y$. age-group, however, after an initial decrease from Period-1 to Period-2, there was a rebound in the prevalence of overall pneumococcal colonization in Period-3 that was largely driven by the increase in prevalence of NVT colonization between Period-3 and Period-2. This may be explained by the fact that following vaccine introduction NVT colonization first established a niche in children before effective transmission to adults occurred. An increase in NVT colonization following an initial decrease was also observed in the Gambia among adults in villages vaccinated with PCV7 ${ }^{11}$. Unlike other settings such as the England and USA ${ }^{26}$, serotype replacement by NVT is not yet complete and competition between NVT and vaccine serotypes such $19 \mathrm{~F}$ and $23 \mathrm{~F}$ is ongoing.

The results of this study should be taken in the context of several limitations. First, we did not examine the impact of carriage of multiple serotypes simultaneously. Second, since we sampled during the same time period (season), we could not assess the impact of seasonal 
trends and we cannot infer whether pneumococcal carriage patterns are similar throughout the year. In addition, the improvement in socioeconomic conditions (including smaller household size) over time, may have influenced the dynamics of pneumococcal colonization and contributed to the overall reduction in pneumococcal carriage. Third, we relied on reported HIV status, and therefore could not assess the impact of HIV on colonization during the PCV13 era.

\section{Conclusion}

In conclusion, four years after the introduction of PCV7 and two years after transitioning to PCV13 in the public childhood immunization program, PCV-serotype colonization continues to decline in children $<5$ years of age. Nevertheless, the residual prevalence of PCV13serotype colonization in childhood age-groups eligible to have been immunized was $>10 \%$ four years following implementation of the vaccine program, indicating ongoing circulation in the community. Our data indicate that the direct and indirect benefits of childhood PCV immunization, particularly in relation to vaccine-serotypes $19 \mathrm{~F}$ and $23 \mathrm{~F}$ have not yet fully materialized. In addition, near complete replacement by NVT is yet to happen, suggesting that the impact of PCV vaccination is yet to be fully realized in this rural setting. Monitoring of colonization prevalence needs to continue in this setting. 


\section{References}

1. Kayhty H, Auranen K, Nohynek H, Dagan R, Makela H. Nasopharyngeal colonization: a target for pneumococcal vaccination. Expert Rev Vaccines. 2006;5(5):651-667.

2. O'Brien KL, Millar EV, Zell ER, et al. Effect of Pneumococcal Conjugate Vaccine on Nasopharyngeal Colonisation among Immunized and Unimmunized Children in a Community Randomized Trial. The Journal of Infectious Diseases. 2007;196:1211-1220.

3. Dagan R, Givon-Lavi N, Zamir O, et al. Reduction of nasopharyngeal carriage of Streptococcus pneumoniae after administration of a 9-valent Pneumococcal Conjugate Vaccine to Toddlers attending day care centers. The Journal of Infectious Diseases. 2002 185:927-936.

4. O'Brien KL, Dagan R, Makela HP, eds. Nasopharyngeal carriage. 1 ed. Washington, DC: American Society for Microbiology press; 2008. Siber GR, Klugman, K.P and Makela, P.H, ed. Pneumococcal vaccines.

5. Cheung Y-B, Zaman, S. M. A.,Nsekpong, E.D.et al. . Nasopharyngeal carriage of Streptococcus pneumoniae in Gambian children who participated in a 9-valent pneumococcal conjugate vaccine trial and their younger siblings. The Pediatric Infectious Disease Journal. 2009;28(11):990-995.

6. *Flasche S, Jan Van Hoek A, Sheasby E, et al. Effect of pneumococcal conjugate vaccination on serotype-specific carriage and invasive disease in England: A cross-sectional study. PLoS Medicine. 2011;8(4):e1001017.

Reports on rapid redcution, and near elimination of PCV-serotypes fowlling intoruction of a 2+1 PCV7/13childhood immunization porgram in England

7. Hammitt LL, Bruden DL, Butler JC, Baggett HC, Hurlburt DA, Reasonover A, et al. Indirect effect of conjugate vaccine on adult carriage of $S$ pneumoniae: an explanation of trends in invasive pneumococcal disease. J Infect Dis. 2006;193:1487-1494.

8. Miller E, Andrews NJ, Waight PA, Slack MP, George RC. Herd immunity and serotype replacement 4 years after seven-valent pneumococcal conjugate vaccination in England and Wales: an observational cohort study. Lancet Infect Dis. 2011;11(10):760-768.

9. *Whitney CG, Farley MM, Hadler J, Harrison LH, Bennett NM, Lynfield R. Decline in invasive pneumococcal disease after the introduction of protein-polysaccharide conjugate vaccine. $N$ Engl J Med. 2003;348:1737-1746.

Illistrates a dramatic indirect effect against vaccine serotype-invasive pneumococcal disease across all agegroups in USA, following introduction of a $3+1$ PCV $7 / 13$ childhood immunization program, with a ctach-up campaign.

10. *Hammitt LL, Akech DO, Morpeth SC, et al. Population effect of 10-valent pneumococcal conjugate vaccine on nasopharyngeal carriage of Streptococcus pneumoniae and nontypeable Haemophilus influenzae in Kilifi, Kenya: findings from cross-sectional carriage studies. Lancet Glob Health. 2014;2(7):70224-70224.

Only immunization program to have introduced PCV10 (three dose priamry series for infants), with a catch-up campaign up to 5-years of age in sub-Saharan Africa; however, still report high residuals prevalence of vaccine-serotype colonization

11. Roca A, Hill P, C., , Townend J, et al. Effects of Community-Wide Vaccination with PCV-7 on Pneumococal Nasopharyngeal Carriage in The Gambia: A Cluster-Randomised Trial. PLoS medicine. 2011;8(10).

12. Gray BM, Converse III GM, Dillon Jr HC. Epidemiologic studies of Streptococcus pneumoniae in Infants: Acquisition, Carriage and Infection during the first 24 mnths of life. The Journal of Infectious Diseases. 1980;142(6):923-933.

13. Nzenze SA, Shiri T, Nunes MC, et al. Temporal changes in pneumococcal colonization in a ruralAfrican community with high HIV-prevalence following routine infant pneumococcalimmunization. Pediatr Infect Dis J. 2013;32(11):1270-1278. 
14. Barron $\mathrm{P}$, Pillay $\mathrm{Y}$, Doherty $\mathrm{T}$, et al. Eliminating mother-to-child HIV transmission in South Africa. Bulletin of the World Health Organization. 2013;91(1):70-74.

15. Nzenze SA, Shiri T, Nunes MC, et al. Temporal association of infant immunisation with pneumococcal conjugate vaccine on the ecology of Streptococcus pneumoniae, Haemophilus influenzae and Staphylococcus aureus nasopharyngeal colonisation in a rural South African community. Vaccine. 2014;32(42):5520-5530.

16. Pelton S, I.,, Weycker D, Klein JO, Strutton D, Ciuryla V, Oster. G. 7-valent pneumococcal conjugate vaccine and lower respiratory tract infections: effectiveness of a 2-dose versus 3dose primary series. Vaccine. 2010;28(6):1575-1582.

17. Roca A, Dione MM, Bojang A, et al. Nasopharyngeal carriage of pneumococci four years after community-wide vaccination with PCV-7 in The Gambia: long-term evaluation of a cluster randomized trial. PLoS One. 2013;8(9).

18. Usuf E, Bottomley C, Bojang E, et al. Persistence of Nasopharyngeal Pneumococcal Vaccine Serotypes and Increase of Nonvaccine Serotypes Among Vaccinated Infants and Their Mothers 5 Years After Introduction of Pneumococcal Conjugate Vaccine 13 in The Gambia. Clin Infect Dis. 2019;68(9):1512-1521.

19. Heinsbroek E, Tafatatha T, Phiri A, et al. Pneumococcal carriage in households in Karonga District, Malawi, before and after introduction of 13-valent pneumococcal conjugate vaccination. Vaccine. 2018;36(48):7369-7376.

20. Whitney CG, Goldblatt D, O'Brien KL. Dosing Schedules for Pneumococcal Conjugate Vaccine: Considerations for Policy Makers. The Pediatric Infectious Disease Journal. 2014;33(Suppl 2 Optimum Dosing of Pneumococcal Conjugate Vaccine For Infants 0 A Landscape Analysis of Evidence Supportin g Different Schedules):S172-S181.

21. $* * *$ Hammitt LL, Etyang AO, Morpeth SC, et al. Effect of ten-valent pneumococcal conjugate vaccine on invasive pneumococcal disease and nasopharyngeal carriage in Kenya: a longitudinal surveillance study. Lancet. 2019;393(10186):2146-2154.

Follow-on from reference 10, which despite having introduced PCV10 with a catch-up campaign (through to 10 yeasr of age), residual prevalence of PCV10 colonization was still $8.8 \%$ (havng shonw a $74 \%$ reduction compared to pre-PCV era. Indicates likley differences in ompact of PCV against colonization (and dynamics of transmission) in high compared to lowmiddle income settings

22. $* * *$ Lourenco J, Obolski U, Swarthout TD, et al. Determinants of high residual post-PCV13 pneumococcal vaccine-type carriage in Blantyre, Malawi: a modelling study. BMC Med. 2019;17(1):219.

Modelling study from urban low-income setting in Balntyre, Malawi, which indicates that suinga 3+0 PCV13 dosing schedule without any catch-up campaign, PCV13 serotype colonization wil only have declined by $75 \%$ across all agegroup ten years post PCV13 introduction (as opposed to near elimination within four years of introduction in high-income settings). Again, indicates likley differences in ompact of PCV against colonization (and dynamics of transmission) in high compared to low-middle income settings.

23. Choi $\mathrm{YH}$, Andrews N, Miller E. Estimated impact of revising the 13-valent pneumococcal conjugate vaccine schedule from $2+1$ to $1+1$ in England and Wales: A modelling study. PLoS medicine. 2019;16(7):e1002845.

24. Blossom DB, Namayanja-Kaye G, al N-MJe. Oropharygeal colonization by Streptococcus pneumoniae among HIV-infected adults in Uganda: assessing prevalence and antimicrobial susceptibility. International Journal of Infectious Diseases. 2006;10:458-464.

25. French N, Gordon SB, Mwalukomo T, et al. A trial of a 7-valent pneumococcal conjugate vaccine in HIV-infected adults. N Engl J Med. 2010;362(9):812-822.

26. Gladstone RA, Jefferies JM, Tocheva AS, et al. Five winters of pneumococcal serotype replacement in UK carriage following PCV introduction. Vaccine. 2015;33(17):2015-2021. 
Table 1. Demographic characteristics and selected health indicators for the study population

\begin{tabular}{|c|c|c|c|c|}
\hline Characteristic & $\begin{array}{l}\text { Period-1 } \\
\text { Pre-PCV era } \\
(2009)\end{array}$ & $\begin{array}{l}\text { Period-2 } \\
\text { PCV7 era } \\
(2011)\end{array}$ & $\begin{array}{l}\text { Period-3 } \\
\text { PCV13 era } \\
(\mathbf{2 0 1 3 )}\end{array}$ & $\begin{array}{l}\text { p-value } \\
\text { (Period-1 vs. } \\
\text { Period-3) }\end{array}$ \\
\hline \multicolumn{5}{|l|}{ Household structure } \\
\hline Number of households & 577 & 1079 & 563 & \\
\hline Total individuals in household (mean $\pm \mathrm{SD}$ ) & $8.8 \pm 4.1$ & $8.8 \pm 4.2$ & $5.6 \pm 2.3$ & $<0.001$ \\
\hline Children $\leq$ 5years $($ mean \pm SD) & $1.8 \pm 1.0$ & $2.0 \pm 1.1$ & $1.5 \pm 0.8$ & 0.014 \\
\hline Individuals $6-18$ years $($ mean \pm SD) & $2.4 \pm 1.8$ & $2.2 \pm 1.7$ & $1.5 \pm 1.4$ & $<0.001$ \\
\hline Individuals $>18$ years $($ mean $\pm \mathrm{SD})$ & $4.6 \pm 2.4$ & $4.7 \pm 2.6$ & $2.5 \pm 1.3$ & $<0.001$ \\
\hline Rooms used for sleeping (mean \pm SD) & $3.2 \pm 1.5$ & $3.2 \pm 1.7$ & $2.6 \pm 1.3$ & $<0.001$ \\
\hline Households with a child that attends day care, $\mathrm{n} / \mathrm{N}(\%)$ & $234 / 569(41.1)$ & $351 / 1078(32.5)$ & $235 / 555(42.3)$ & 0.68 \\
\hline \multicolumn{5}{|l|}{ Fuel used for cooking, $n / \mathbf{N}(\%)$} \\
\hline Coal/Wood & $394 / 564(69.9)$ & $685 / 1066(64.3)$ & $235 / 535(43.8)$ & $<0.001$ \\
\hline Paraffin/Gas & $11 / 564(1.9)$ & $17 / 1066(1.6)$ & $2 / 535(0.4)$ & 0.020 \\
\hline Electricity & $159 / 564(28.2)$ & $364 / 1066(34.1)$ & $299 / 535(55.8)$ & $<0.001$ \\
\hline \multicolumn{5}{|l|}{ Children $\leq 144$ months of age } \\
\hline Number of participants & 982 & 1814 & 944 & \\
\hline Female, N (\%) & $494(50.3)$ & $931(51.3)$ & $439(46.5)$ & 0.10 \\
\hline Overall age in months (mean \pm SD) & $48.4 \pm 37.7)$ & $42.0 \pm 35.9)$ & $42.5 \pm 34.5)$ & \\
\hline$\leq 3$ months $($ mean $\pm \mathrm{SD}) ; \mathrm{n}$ & Not applicable & $1.9 \pm 0.82 ; 9$ & $1.8 \pm 0.81 ; 7$ & \\
\hline 3-9 months (mean $\pm \mathrm{SD}) ; \mathrm{n}$ & Not applicable & $6.8 \pm 1.7 ; 71$ & $6.2 \pm 2.0 ; 23$ & \\
\hline$>9-23$ months (mean $\pm \mathrm{SD}) ; \mathrm{n}$ & $17.3 \pm 3.9 ; 399$ & $17.1 \pm 4.0 ; 828$ & $17.5 \pm 4.1 ; 404$ & \\
\hline 24-59 months (mean $\pm \mathrm{SD}) ; \mathrm{n}$ & $38.1 \pm 11.6 ; 273$ & $37.1 \pm 11.4 ; 422$ & $36.3 \pm 11.6 ; 259$ & \\
\hline 60-144 months (mean $\pm \mathrm{SD}) ; \mathrm{n}$ & $97.4 \pm 25.0 ; 310$ & $94.8 \pm 24.4 ; 484$ & $93.5 \pm 21.8 ; 251$ & \\
\hline HIV-infected (self-reported), n/N (\%) & $5 / 163(3.1)$ & $20 / 625(3.2)$ & $15 / 503(3.0)$ & 0.96 \\
\hline Child ever breastfed, overall, $\mathrm{n} / \mathrm{N}(\%)$ & $717 / 779(92.0)$ & $1181 / 1398(84.5)$ & $769 / 932(82.5)$ & $<0.001$ \\
\hline$<12$ months. & 9/17 (52.9) & $30 / 59(50.9)$ & $52 / 66(78.8)$ & 0.03 \\
\hline $12-24$ months & $156 / 182(85.7)$ & $342 / 456(75.0)$ & $297 / 363(81.8)$ & 0.25 \\
\hline Child attending day-care, $\mathrm{n} / \mathrm{N}(\%)$ & $378 / 981(38.5)$ & $648 / 1811(35.8)$ & $398 / 929(42.8)$ & 0.06 \\
\hline Child with tuberculosis, n/N (\%) & $3 / 977(0.3)$ & $2 / 1805(0.1)$ & $7 / 930(0.8)$ & 0.18 \\
\hline Child on previous TB treatment, $\mathrm{n} / \mathrm{N}(\%)$ & $4 / 981(0.4)$ & $4 / 1808(0.2)$ & $9 / 920(1.0)$ & 0.13 \\
\hline Child on antibiotics, $\mathrm{n} / \mathrm{N}(\%)$ & $38 / 981(7.7)$ & $96 / 1801(5.3)$ & $14 / 919(1.5)$ & 0.002 \\
\hline
\end{tabular}




\begin{tabular}{|c|c|c|c|c|}
\hline Child ever hospitalised, n/N (\%) & $14 / 974(1.4)$ & $9 / 1804(0.5)$ & $11 / 931(1.2)$ & 0.62 \\
\hline Presence of a smoker in the household, $\mathrm{n} / \mathrm{N}(\%)$ & $214 / 977(21.9)$ & $602 / 1770(34.0)$ & 173/927 (18.7) & 0.08 \\
\hline \multicolumn{5}{|l|}{ PCV immunization status, $n / \mathbf{N}(\%)$} \\
\hline \multicolumn{5}{|l|}{$3-9$ months } \\
\hline zero doses & \multirow{5}{*}{ Not applicable } & $7 / 71(9.9)$ & $1 / 23(4.3)$ & \\
\hline one dose & & $18 / 71(25.4)$ & $6 / 23(26.1)$ & \\
\hline two doses & & $32 / 71(45.1)$ & $15 / 23(65.2)$ & \\
\hline three doses & & $2 / 71(2.8)$ & $0 / 23(0.0)$ & \\
\hline No vaccination information & & $12 / 71(16.9)$ & $1 / 23(4.3)$ & \\
\hline \multicolumn{5}{|l|}{$>9-23$ months } \\
\hline zero doses & $399 / 399(0)$ & $50 / 828(6.0)$ & $13 / 404(3.2)$ & \\
\hline one dose & & $107 / 828(12.9)$ & $8 / 404(2.0)$ & \\
\hline two doses & & $191 / 828(23.1)$ & $25 / 404(6.2)$ & \\
\hline three doses & & $313 / 828(37.8)$ & $332 / 404(82.2)$ & \\
\hline No vaccination information & +8 & $167 / 828(20.2)$ & $26 / 404(6.4)$ & \\
\hline \multicolumn{5}{|l|}{24 to 59 months } \\
\hline zero doses & $273 / 273(0.0)$ & $205 / 422(48.6)$ & $48 / 259(18.5)$ & \\
\hline one dose & 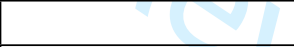 & $17 / 422(4.0)$ & $21 / 259(8.1)$ & \\
\hline two doses & Q & $30 / 422(7.1)$ & $34 / 259(13.1)$ & \\
\hline three doses & & $34 / 422(8.1)$ & $129 / 259(49.8)$ & \\
\hline No vaccination information & & $136 / 422(32.2)$ & $27 / 259(10.4)$ & \\
\hline \multicolumn{5}{|l|}{ Participants aged $>12$ years $(y$.$) of age$} \\
\hline Number of participants & 1028 & 1845 & 940 & \\
\hline Female, N (\%) & $828(80.5)$ & $1563(84.7)$ & $752(80.0)$ & 0.76 \\
\hline Overall age in years (mean $\pm \mathrm{SD})$ & $33.3 \pm 16.7$ & $32.6 \pm 16.5$ & $31.8 \pm 16.0$ & 0.040 \\
\hline$>12-18$ years., $($ mean $\pm S D) ; n$ & $15.0 \pm 1.8 ; 158$ & $14.9 \pm 1.9 ; 285$ & $14.3 \pm 1.7 ; 177$ & 0.001 \\
\hline$>18-45$ years, $($ mean \pm SD $) ; n$ & $28.2 \pm 7.3 ; 633$ & $28.3 \pm 7.2 ; 1188$ & $29.6 \pm 6.5 ; 615$ & 0.001 \\
\hline$>45$ years, $($ mean $\pm S D) ; n$ & $59.1 \pm 10.3 ; 237$ & $60.2 \pm 10.7 ; 372$ & $62.1 \pm 11.4 ; 148$ & 0.008 \\
\hline HIV-infected in those self-reporting, $\mathrm{n} / \mathrm{N}(\%)$ & 40/504 (7.9) & $135 / 1318(10.2)$ & $64 / 745(22.0)$ & $<0.001$ \\
\hline$>12-18$ years & $0 / 24(0)$ & $1 / 88(1.1)$ & $8 / 79(10.1)$ & \\
\hline$\geq 18$ years & $40 / 480(8.3)$ & $134 / 1230(10.9)$ & $156 / 667(23.4)$ & \\
\hline HIV-infected in those tested, $\mathrm{n} / \mathrm{N}(\%)$ & & & $94 / 463(20.36 . \%)$ & \\
\hline$>12-18$ years & Not done & Not done & $2 / 7(28.6)$ & \\
\hline$\geq 18$ years & Not done & Not done & $92 / 456(20.2)$ & \\
\hline On antiretroviral therapy, $\mathrm{n} / \mathrm{N}(\%)$ & $21 / 38(55.3)$ & $75 / 123(61.0)$ & $109 / 154(70.8)$ & 0.53 \\
\hline
\end{tabular}




\begin{tabular}{|l|l|l|l|l|}
\hline Smoker, $\mathrm{n} / \mathrm{N}(\%)$ & $17 / 994(1.7)$ & $26 / 1779(1.5)$ & $21 / 935(2.2)$ \\
\hline Sniffing tobacco, n/N (\%) & $27 / 993(2.7)$ & $39 / 1780(2.2)$ & $19 / 931(2.0)$ \\
\hline Drink alcohol, n/N (\%) & $104 / 994(10.5)$ & $114 / 1778(6.4)$ & $83 / 929(8.9)$ \\
\hline With chronic illness, n/N (\%) & $138 / 991(13.9)$ & $199 / 1775(11.2)$ & $179 / 927(19.3)$ & 0.33 \\
\hline On tuberculosis treatment, n/N (\%) & $7 / 792(0.9)$ & $10 / 1770(0.6)$ & $9 / 934(1.0)$ & 0.002 \\
\hline On cotrimoxazole, n/N (\%) & $4 / 35(11.4)$ & $8 / 101(7.9)$ & 0.86 & $0 / 54(0.0)$ \\
\hline
\end{tabular}

$\chi^{2}-$ used to compare proportions between the two periods

TTEST used to compare the differences between means between two periods

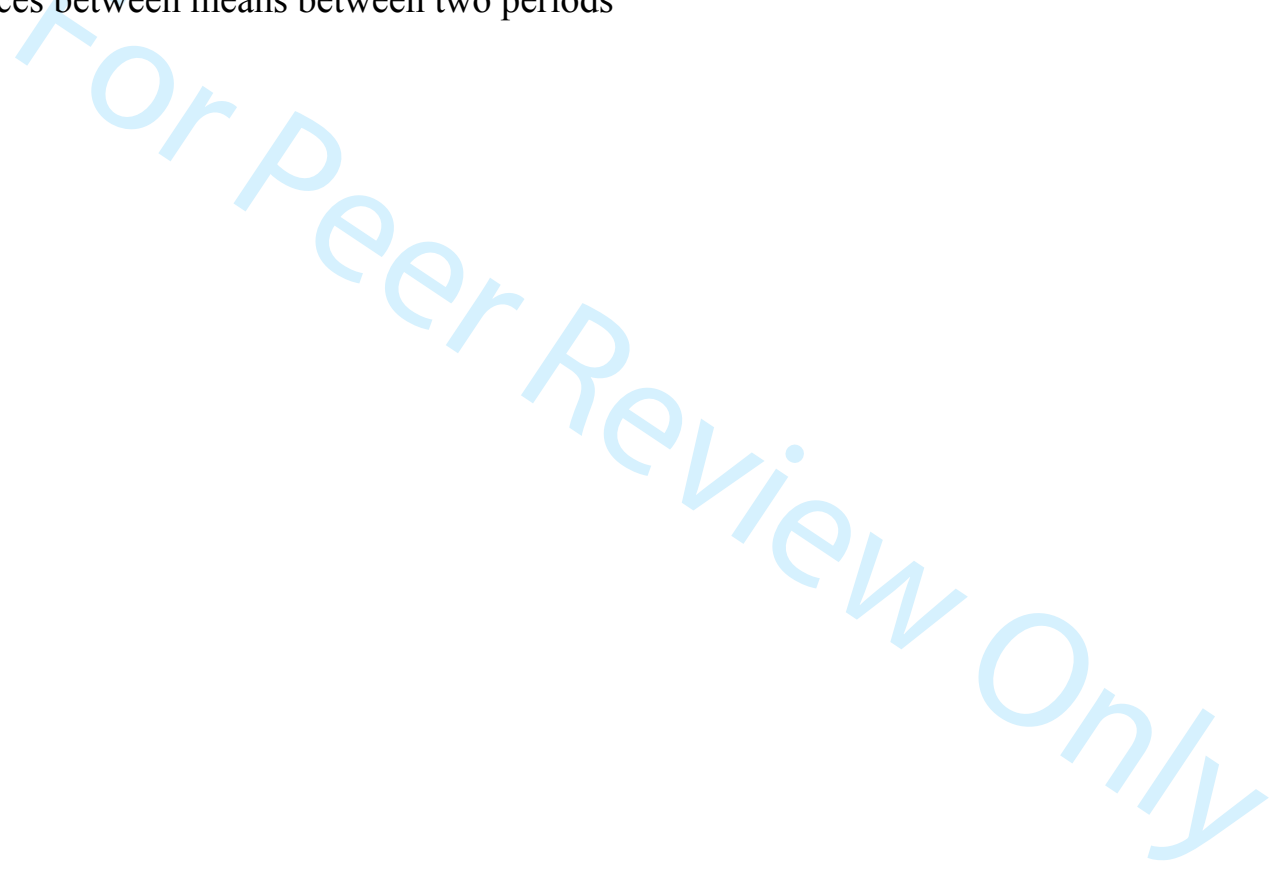


Table 2. Comparison of prevalence of all pneumococci, PCV7-serotypes, additional PCV13 serotypes and non-PCV13 serotypes by age-group in the three study periods

\begin{tabular}{|c|c|c|c|c|c|c|c|c|c|c|c|c|c|c|c|}
\hline \multirow[t]{2}{*}{ Age-group } & \multicolumn{3}{|c|}{$\begin{array}{c}\text { Total per age-group } \\
\mathrm{N}(\%)^{1}\end{array}$} & \multicolumn{3}{|c|}{$\begin{array}{c}\text { Overall colonisation } \\
\text { n }(\%)^{2}\end{array}$} & \multicolumn{3}{|c|}{$\begin{array}{c}\text { PCV7 serotypes } \\
\text { n }(\%)^{2}\end{array}$} & \multicolumn{3}{|c|}{\begin{tabular}{|c} 
PCV13 additional-6 serotypes \\
n (\%)
\end{tabular}} & \multicolumn{3}{|c|}{$\begin{array}{c}\text { Non PCV13 serotypes } \\
\text { n }(\%)^{2}\end{array}$} \\
\hline & Period-1 & Period-2 & Period-3 & Period-1 & Period-2 & Period-3 & Period-1 & Period-2 & Period-3 & Period-1 & Period-2 & Period-3 & Period-1 & Period-2 & Period-3 \\
\hline All age-groups & 2010 & 3659 & 1884 & $852(42.4)$ & $1341(36.6)$ & $675(35.8)$ & $368(18.3)$ & $418(11.4)$ & $129(6.8)$ & $159(7.9)$ & $272(7.4)$ & $53(2.8)$ & $369(18.4)$ & $705(19.3)$ & $502(26.6)$ \\
\hline $\operatorname{AOR}^{3}(95 \% \mathrm{CI}), \mathrm{p}$-value & & & (2) & \multicolumn{3}{|c|}{$0.80(0.74,0.86),<0.001$} & \multicolumn{3}{|c|}{$0.34(0.27,0.44),<0.001$} & \multicolumn{3}{|c|}{$0.34(0.23,0.49),<0.001$} & \multicolumn{3}{|c|}{$1.49(1.27,1.74),<0.001$} \\
\hline All age-groups & 2010 & 3579 & 1854 & $852(42.4)$ & $1283(35.8)$ & $661(35.7)$ & $368(18.3)$ & $398(11.1)$ & $127(6.9)$ & $159(7.9)$ & $262(7.3)$ & $49(2.6)$ & $369(18.4)$ & $674(18.8)$ & $494(26.6)$ \\
\hline ARR $(95 \%$ CI $), p-$ value $^{4}$ & & & & \multicolumn{3}{|c|}{$0.81(0.75,0.88),<0.001$} & \multicolumn{3}{|c|}{$0.35(0.27,0.45),<0.001$} & \multicolumn{3}{|c|}{$0.33(0.23,0.48),<0.001$} & \multicolumn{3}{|c|}{$1.51(1.29,1.76),<0.001$} \\
\hline \multirow[t]{2}{*}{$\leq 9$ months } & $\mathrm{ND}^{5}$ & $80(2.2)$ & $30(1.6)$ & ND & $58(72.5)$ & $14(46.7)$ & ND & $20(25.0)$ & $2(6.7)$ & ND & $10(12.5)$ & $4(13.3)$ & ND & $31(38.8)$ & $8(26.7)$ \\
\hline & & & & \multicolumn{3}{|c|}{$0.61(0.40,0.93), 0.02$} & \multicolumn{3}{|c|}{$0.27(0.05,0.90), 0.03$} & \multicolumn{3}{|c|}{$1.07(0.36,3.16), 0.90$} & \multicolumn{3}{|c|}{$0.67(0.35,1.28) \cdot 0.23$} \\
\hline$>9-23 n$ & $399(19.9)$ & 828( & $04(21.4)$ & $331(83.0)$ & $661(79.8)$ & 268( & $180(45.1)$ & $212(25.6)$ & $54(1$ & $62(15.5)$ & $137(16.5)$ & $20(5.0)$ & $108(27.1)$ & $342(41.3)$ & $196(48.5)$ \\
\hline $\operatorname{ARR}(95 \% \mathrm{CI})$ & & & & \multicolumn{3}{|c|}{$0.79(0.72,0.88),<0.001$} & \multicolumn{3}{|c|}{$0.26(0.19,0.37),<0.001$} & \multicolumn{3}{|c|}{$0.28(0.16,0.50),<0.001$} & \multicolumn{3}{|c|}{$2.06(1.63,2.61),<0.001$} \\
\hline 24-59 months & $273(13.6)$ & $1.5)$ & $9(13.7)$ & $219(80.2)$ & $307(72.7)$ & 175 & $97(35.5)$ & $121(28.7)$ & $38(1$ & $41(15)$ & $64(15.2)$ & $13(5)$ & $90(33)$ & $135(32)$ & $127(49)$ \\
\hline ARR $(95 \% \mathrm{CI}), \mathrm{p}$-value & & & & \multicolumn{3}{|c|}{$0.84(0.74,0.96), 0.009$} & \multicolumn{3}{|c|}{$0.37(0.24,0.56),<0.001$} & \multicolumn{3}{|c|}{$0.40(0.21,0.76), 0.005$} & \multicolumn{3}{|c|}{$1.60(1.24,2.07), 0.003$} \\
\hline$>9-59$ months & $672(33.4)$ & $1250(34.2)$ & $63(35.2)$ & $550(81.8)$ & $915(73.2)$ & $431(65.0)$ & $277(41.2)$ & $314(25.1)$ & $90(13.6)$ & $103(15.3)$ & $192(15.4)$ & $29(4.4)$ & $198(29.5)$ & $449(35.9)$ & $317(47.8)$ \\
\hline $\operatorname{ARR}(95 \% \mathrm{CI}), \mathrm{p}$ & & & & \multicolumn{3}{|c|}{$0.81(0.75,0.89),<0.001$} & 0.30 & $0.23,0.40)$ & .001 & $0.34(0$ & 0.22 & $<0.001$ & $1.84(1$ & $.54,2.19),<($ & 0.001 \\
\hline $60-14$ & & & 3.3) & $186(60)$ & $242(50)$ & $130(51.8)$ & $59(19.0)$ & $61(12.6)$ & 25( & $34(11.0)$ & $50(10.3)$ & $14(5.6)$ & $103(33.2)$ & $138(28.5)$ & $93(37.1)$ \\
\hline ARR & & & & 0.8 & $(0.69,0.98)$ & .03 & 0.5 & $(0.36,0.98)$ & .04 & 0.41 & $(0.20,0.81)$ & 0.01 & 1.04 & $(0.77,1.41),($ & 0.78 \\
\hline$>9-14$ & $3.9)$ & 4) & 18.5) & $736(74.9)$ & $1157(66.7)$ & 561( & $336(34.2)$ & $375(21.6)$ & $115(12.6)$ & $137(14.0)$ & $+.0)$ & $43(4.7)$ & $301(30.7)$ & $587(33.9)$ & 410 \\
\hline ARR $(95 \% \mathrm{CI}), \mathrm{p}$-value & & & & 0.81 & $0.75,0.88)$ & .001 & 0.32 & $0.25,0.41)$ & .001 & $0.35(0$ & $0.24,0.51)$ & $<0.001$ & 16201 & $.38,1.90),<($ & 0.001 \\
\hline & & & & & & & & & & & & & & & \\
\hline$>12-$ & 9) & 8) & (9.4) & $2.8)$ & $35(12.3)$ & & .7) & $6(2.1)$ & $6(3.4)$ & $9(5.7)$ & $7(2.5)$ & $2(1.1)$ & $19(12)$ & $22(7.7)$ & $20(11.3)$ \\
\hline $\operatorname{ARR}(95 \% \mathrm{CI})$ & & & & 0.5 & $(0.35,0.97)$, & .04 & 0.6 & $(0.22,1.88$ & 42 & 0.11 & $(0.01,0.96)$ &, 0.04 & 0.75 & $.38,1.48),($ & 0.41 \\
\hline$>18-45$ years & $633(31.5)$ & $1188(32.5)$ & $(32.6)$ & $68(10.7)$ & $69(5.8)$ & $64(10.4)$ & $(3.0)$ & $13(1.1)$ & $6(1.0)$ & $12(1.9)$ & $10(0.8)$ & $4(0.7)$ & $42(6.6)$ & $49(4.1)$ & $55(8.9)$ \\
\hline ARR $(95 \% \mathrm{CI})$ & & & & & $0.61,1.40$ & & & $0.06,0.75$ & & 0.27 & $(0.09,0.88)$ &, 0.03 & & $.71,1.88),($ & 0.55 \\
\hline$>45$ years & $237(11.8)$ & $372(10.2)$ & $148(7.9)$ & $12(5.1)$ & $22(5.9)$ & $9(6.1)$ & .7) & $4(1.1)$ & $0(0.0)$ & $1(0.4)$ & $3(0.8)$ & $0(0.0)$ & $7(3)$ & $16(4.3)$ & $9(6.1)$ \\
\hline ARR $(95 \%$ & & & & & $(0.50,3.05$ & .65 & & - & & & - & & 2.0 & $(0.78,5.39),($ & 0.14 \\
\hline$>12$ years & $1028(51.1)$ & $1845(50.4)$ & $940(49.9)$ & $116(11.3)$ & $126(6.8)$ & $100(10.6)$ & $2(3.1)$ & $23(1.2)$ & $12(1.3)$ & $22(2.1)$ & $20(1.1)$ & $6(0.6)$ & $68(6.6)$ & $87(4.7)$ & $84(8.9)$ \\
\hline ARR $(95 \% \mathrm{CI}), \mathrm{p}$-value & & & & 0.8 & $(0.64,1.18)$, & & & $(0.18,0.82)$ & & 0.25 & $(0.07,0.89)$ & 0.03 & & $0.82,1.71),($ & 0.37 \\
\hline
\end{tabular}

${ }^{1}$ Value in parenthesis indicate percentage of individuals in each age-group. ${ }^{2}$ Value in parenthesis indicate percentage of positive individuals.

${ }^{3} \mathrm{ARR}=$ adjusted risk ratio: variables adjusted for: age, gender, period, presence of a smoker in the household, fuel used for cooking and household structure. ${ }^{4}$ Total excludes infants $\leq 9$ months of age. ${ }^{5} \mathrm{ND}=$ Not done, infants $\leq 9$ months of age were not sampled in Period-1, therefore comparison is for 2011 versus 2013. 
Table 3. Individual serotype prevalence by age-group in children and adults over the three study periods

\begin{tabular}{|c|c|c|c|c|c|c|c|c|c|c|c|c|c|c|c|c|c|c|c|c|}
\hline \multicolumn{2}{|c|}{ Serotype } & \multicolumn{15}{|c|}{ Children } & \multirow{2}{*}{\multicolumn{4}{|c|}{$\begin{array}{c}\text { Adults } \\
12 \text { years }\end{array}$}} \\
\hline & & \multicolumn{3}{|c|}{$>9-23$ months } & \multicolumn{4}{|c|}{ 24-59 months } & \multicolumn{4}{|c|}{$>9-59$ months } & \multicolumn{4}{|c|}{ 60-144 months } & & & & \\
\hline & Period-1 & Period-2 & Period-3 & $\begin{array}{l}\text { p- } \\
\text { value }\end{array}$ & Period-1 & Period-2 & Period-3 & $\begin{array}{c}\text { p- } \\
\text { value }\end{array}$ & Period-1 & \begin{tabular}{|l|} 
Period-2 \\
\end{tabular} & \begin{tabular}{|l|} 
Period-3 \\
\end{tabular} & $\begin{array}{c}\text { p- } \\
\text { value }\end{array}$ & \begin{tabular}{|l|} 
Period-1 \\
\end{tabular} & \begin{tabular}{|l|} 
Period-2 \\
\end{tabular} & \begin{tabular}{|l|} 
Period-3 \\
\end{tabular} & $\begin{array}{c}\text { p- } \\
\text { value }\end{array}$ & \begin{tabular}{|l|} 
Period-1 \\
\end{tabular} & Period-2 & Period-3 & $\begin{array}{c}\text { p- } \\
\text { value }\end{array}$ \\
\hline & $\mathrm{N}=399$ & $=828$ & $\mathrm{~N}=404$ & & $=273$ & $=422$ & $=259$ & & $=672$ & $\mathrm{~N}=1250$ & $\mathrm{~N}=663$ & & $=310$ & $\mathrm{~N}=484$ & $\mathrm{~N}=251$ & & $\mathrm{~J}=1028$ & $\mathrm{~N}=1845$ & $\mathrm{~N}=940$ & \\
\hline & $\mathrm{n}(\%)$ & $\mathrm{n}(\%)$ & $(\%)$ & & $\mathrm{n}(\%)$ & $(\%)$ & $(\%)$ & & $\mathrm{n}(\%)$ & $\mathrm{n}(\%)$ & $\mathrm{n}(\%)$ & & $(\%)$ & $\mathrm{n}(\%)$ & $\mathrm{n}(\%)$ & & $\mathrm{n}(\%)$ & $\mathrm{n}(\%)$ & $\mathrm{n}(\%)$ & \\
\hline \multicolumn{21}{|c|}{ PCV7 serotypes } \\
\hline 4 & $3(0.8)$ & $(0.6)$ & $(0.5)$ & 0.64 & $2(0.7)$ & $5(1.2)$ & $(0.4)$ & 0.59 & $5(0.7)$ & $10(0.8)$ & $(0.5)$ & 0.49 & 2.9) & $3(0.6)$ & $(0.0)$ & 0.007 & $5(0.5)$ & $2(0.1)$ & $2(0.2)$ & 0.31 \\
\hline $6 \mathrm{~B}$ & $52(13.0)$ & $39(4.7)$ & $2.0)$ & $<0.001$ & $16(5.9)$ & $24(5.7)$ & (1.2) & 0.003 & $68(10.1)$ & $63(5)$ & $11(1.7)$ & $<0.001$ & $13(4.2)$ & $10(2.1)$ & $5(2.0)$ & 0.14 & $5(0.5)$ & & $3(0.3)$ & 0.56 \\
\hline $9 \mathrm{~V}$ & $(1.8)$ & $5(0.6)$ & $(0.5)$ & 0.09 & $6(2.2)$ & $7(1.7)$ & $3(1.2)$ & 0.35 & $13(1.9)$ & $12(1.0)$ & $5(0.8)$ & 0.06 & $5(1.6)$ & $5(1)$ & $2(0.8)$ & .39 & $3(0.3)$ & .2) & $1(0.1)$ & 0.36 \\
\hline 14 & $(5)$ & $29(3.5)$ & $(0.0)$ & $<0.001$ & $9(3.3)$ & $11(2.6)$ & $1(0.4)$ & 0.010 & $29(4.3)$ & $40(3.2)$ & $1(0.2)$ & $<0.001$ & $.3)$ & $9(1.9)$ & $0(0.0)$ & .07 & $3(0.3)$ & .2) & $0(0.0)$ & 0.10 \\
\hline $18 \mathrm{C}$ & $5(1.3)$ & $1(0.1)$ & $(0.2)$ & 0.10 & $5(1.8)$ & $3(0.7)$ & $0(0.0)$ & 0.030 & $10(1.5)$ & $4(0.3)$ & $1(0.2)$ & 0.007 & $1(0.3)$ & $2(0.4)$ & $1(0.4)$ & .88 & $.4)$ & $.1)$ & $0(0.0)$ & 0.06 \\
\hline $19 \mathrm{~F}$ & $63(15.8)$ & $77(9.3)$ & $24(5.9)$ & $<0.001$ & $37(13.6)$ & $47(11.1)$ & $18(6.9)$ & 0.010 & $100(14.9)$ & $124(9.9)$ & $42(6.3)$ & $<0.001$ & 13 & .3) & $11(4.4)$ & .91 & $6(0.6)$ & & .3) & 0.39 \\
\hline $23 \mathrm{~F}$ & $34(8.5)$ & $39(4.7)$ & $15(3.7)$ & 0.004 & $23(8.4)$ & $28(6.6)$ & $12(4.6)$ & 0.08 & $57(8.5)$ & $67(5.4)$ & $27(4.1)$ & 0.001 & $.5)$ & .3) & $8(3.2)$ & 0.42 & $6(0.6)$ & & $3(0.3)$ & 0.39 \\
\hline \multicolumn{21}{|c|}{ Additional six serotypes in PCV13 } \\
\hline 1 & $1(0.3)$ & $1(0.1)$ & $0(0.0)$ & 0.31 & $2(0.7)$ & $0(0.0)$ & $1(0.4)$ & 0.59 & $3(0.4)$ & $1(0.1)$ & $(0.2)$ & 0.32 & $(0.0)$ & $1(0.2)$ & $0(0.0)$ & & $0(0.0)$ & $0(0.0)$ & $0(0.0)$ & \\
\hline 3 & 1 & $6(0.7)$ & $2(0.5)$ & 0.57 & $8(2.9)$ & $7(1.7)$ & $3(1.2)$ & 0.15 & $9(1.3)$ & $13(1.0)$ & $(0.8)$ & 0.29 & $12(3.9)$ & $14(2.9)$ & $9(3.6)$ & 0.86 & $10(1.0)$ & $11(0.6)$ & $2(0.2)$ & 0.030 \\
\hline 5 & $(0.0)$ & $0(0.0)$ & $0(0.0)$ & & $2(0.7)$ & $(0.0)$ & $(0.0)$ & 0.17 & $2(0.3)$ & $0(0.0)$ & $0(0.0)$ & 0.16 & 0( & $0(0.0)$ & $0(0.0)$ & & $0(0.0)$ & $.0)$ & $1(0.1)$ & 0.30 \\
\hline $6 \mathrm{~A}$ & $37(9.3)$ & $81(9.8)$ & $7(1.7)$ & $<0.001$ & $23(8.4)$ & $42(10)$ & (1.2) & $<0.001$ & $60(8.9)$ & $123(9.8)$ & $10(1.5)$ & $<0.001$ & $14(4.5)$ & $28(5.8)$ & $1(0.4)$ & 0.003 & $5(0.5)$ & $8(0.4)$ & $1(0.1)$ & 0.13 \\
\hline $7 \mathrm{~F}$ & $0(0.0)$ & $1(0.1)$ & $0(0.0)$ & & $0(0.0)$ & $0(0.0)$ & $(0.0)$ & & $0(0.0)$ & $1(0.1)$ & $0(0.0)$ & & $0(0.0)$ & $0(0.0)$ & $0(0.0)$ & & $0(0.0)$ & $0(0.0)$ & $0(0.0)$ & \\
\hline $19 \mathrm{~A}$ & $23(5.8)$ & $42(5.1)$ & $7(1.7)$ & .003 & $8(2.9)$ & $16(3.8)$ & $6(2.3)$ & 0.66 & $31(4.6)$ & $58(4.6)$ & $13(2.0)$ & 0.007 & $9(2.9)$ & $8(1.7)$ & $4(1.6)$ & 0.31 & $7(0.7)$ & $2(0.1)$ & $2(0.2)$ & 0.12 \\
\hline \multicolumn{21}{|c|}{ Non-PCV13 serotypes } \\
\hline 8 & 5) & $2(0.2)$ & $(00)$ & & $0)$ & $(0.2)$ & .4) & 30 & .3) & $3(0.2)$ & $(0.2)$ & 0.5 & $.6)$ & $5(1)$ & $7(2.8)$ & 0.34 & $0(0.0)$ & $5(0.3)$ & $6(0.6)$ & 0.010 \\
\hline $9 \mathrm{~N}$ & $3(0.8)$ & $7(0.8)$ & $(0.9)$ & 0.99 & $1(0.4)$ & $3(0.7)$ & $2(0.8)$ & 0.53 & $4(0.6)$ & $10(0.8)$ & $5(0.8)$ & 0.7 & $2(0.6)$ & $3(0.6)$ & $4(1.6)$ & 0.28 & $3(0.3)$ & $2(0.1)$ & $2(0.2)$ & 0.73 \\
\hline $11 \mathrm{~A}$ & $4(1.0)$ & $18(2.2)$ & $16(4.0)$ & 0.007 & $11(4.0)$ & $5(1.2)$ & $6(2.3)$ & 0.26 & $15(2.2)$ & $23(1.8)$ & $22(3.3)$ & 0.23 & $10(3.2)$ & $2(0.4)$ & $6(2.4)$ & 0.55 & $3(0.3)$ & $5(0.3)$ & $6(0.6)$ & 0.26 \\
\hline $12 \mathrm{~F}$ & $3(0.8)$ & $3(0.4)$ & $1(0.2)$ & 0.31 & $0(0.0)$ & $1(0.2)$ & $0(0.0)$ & & $3(0.4)$ & $4(0.3)$ & $1(0.2)$ & 0.32 & $0(0.0)$ & $4(0.8)$ & $1(0.4)$ & 0.27 & $1(0.1)$ & $1(0.1)$ & $1(0.1)$ & 0.95 \\
\hline 13 & $11(2.8)$ & $20(2.4)$ & $17(4.2)$ & 0.26 & $5(1.8)$ & $12(2.8)$ & $6(2.3)$ & 0.69 & $16(2.4)$ & $32(2.6)$ & $23(3.5)$ & 0.24 & $6(1.9)$ & $14(2.9)$ & $2(0.8)$ & 0.26 & $4(0.4)$ & $4(0.2)$ & $1(0.1)$ & 0.21 \\
\hline $15 \mathrm{~A}$ & $2(0.5)$ & $17(2.1)$ & $10(2.5)$ & 0.020 & $2(0.7)$ & $8(1.9)$ & $6(2.3)$ & 0.13 & $4(0.6)$ & $25(2.0)$ & $16(2.4)$ & 0.006 & $0(0.0)$ & $5(1)$ & $3(1.2)$ & 0.05 & $1(0.1)$ & $6(0.3)$ & $2(0.2)$ & 0.51 \\
\hline $15 \mathrm{~B}$ & $13(3.3)$ & $48(5.8)$ & $13(3.2)$ & 0.97 & $15(5.5)$ & $16(3.8)$ & $10(3.9)$ & 0.37 & $28(4.2)$ & $64(5.1)$ & $23(3.5)$ & 0.51 & $12(3.9)$ & $3(0.6)$ & $4(1.6)$ & 0.11 & $1(0.1)$ & $3(0.2)$ & $1(0.1)$ & 0.95 \\
\hline $15 \mathrm{C}$ & $6(1.5)$ & $12(1.4)$ & $14(3.5)$ & 0.07 & $8(2.9)$ & $3(0.7)$ & $11(4.2)$ & 0.41 & $14(2.1)$ & $15(1.2)$ & $25(3.8)$ & 0.07 & $1(0.3)$ & $7(1.4)$ & $3(1.2)$ & 0.22 & $2(0.2)$ & $5(0.3)$ & $1(0.1)$ & 0.62 \\
\hline $16 \mathrm{~F}$ & $4(1.0)$ & $40(4.8)$ & $21(5.2)$ & 0.001 & $1(0.4)$ & $13(3.1)$ & $16(6.2)$ & $<0.001$ & $5(0.7)$ & $53(4.2)$ & $37(5.6)$ & $<0.001$ & $8(2.6)$ & $13(2.7)$ & $10(4.0)$ & 0.35 & $4(0.4)$ & $7(0.4)$ & $6(0.6)$ & 0.44 \\
\hline 21 & $0(0.0)$ & $8(1.0)$ & $5(1.2)$ & 0.030 & $1(0.4)$ & $3(0.7)$ & $6(2.3)$ & 0.050 & $1(0.1)$ & $11(0.9)$ & $11(1.7)$ & 0.003 & $2(0.6)$ & $2(0.4)$ & $6(2.4)$ & 0.08 & $3(0.3)$ & $5(0.3)$ & $3(0.3)$ & 0.91 \\
\hline $23 \mathrm{~A}$ & $2(0.5)$ & $3(0.4)$ & $6(1.5)$ & 0.16 & $1(0.4)$ & $4(0.9)$ & $2(0.8)$ & 0.53 & $3(0.4)$ & $7(0.6)$ & $8(1.2)$ & 0.12 & $1(0.3)$ & $3(0.6)$ & $0(0.0)$ & 0.37 & $0(0.0)$ & $0(0.0)$ & $1(0.1)$ & 0.30 \\
\hline $23 \mathrm{~B}$ & $13(3.3)$ & $16(1.9)$ & $8(2.0)$ & 0.26 & $9(3.3)$ & $8(1.9)$ & $5(1.9)$ & 0.33 & $22(3.3)$ & $24(1.9)$ & $13(2.0)$ & 0.13 & $7(2.3)$ & $2(0.4)$ & $5(2.0)$ & 0.83 & $2(0.2)$ & $0(0.0)$ & $2(0.2)$ & 0.93 \\
\hline 34 & $7(1.8)$ & $26(3.1)$ & $22(5.4)$ & 0.005 & $11(4.0)$ & $15(3.6)$ & $23(8.9)$ & 0.020 & $18(2.7)$ & $41(3.3)$ & $45(6.8)$ & $<0.001$ & $9(2.9)$ & $8(1.7)$ & $12(4.8)$ & 0.24 & $6(0.6)$ & $5(0.3)$ & $4(0.4)$ & 0.62 \\
\hline $35 \mathrm{~B}$ & $3(0.8)$ & $15(1.8)$ & $23(5.7)$ & $<0.001$ & $1(0.4)$ & $6(1.4)$ & $8(3.1)$ & 0.010 & $4(0.6)$ & $21(1.7)$ & $31(4.7)$ & $<0.001$ & $1(0.3)$ & $10(2.1)$ & $12(4.8)$ & 0.001 & $0(0.0)$ & $2(0.1)$ & $13(1.4)$ & $<0.001$ \\
\hline NT & $12(3.0)$ & $20(2.4)$ & $0(0.0)$ & $<0.001$ & $6(2.2)$ & $8(1.9)$ & $0(0.0)$ & 0.020 & $18(2.7)$ & $28(2.2)$ & $0(0.0)$ & $<0.001$ & $2(0.6)$ & $4(0.8)$ & $0(0.0)$ & 0.20 & $1(0.1)$ & $11(0.6)$ & $0(0.0)$ & 0.34 \\
\hline OTH & $28(7.0)$ & $70(8.5)$ & $34(8.4)$ & 0.46 & $23(8.4)$ & $37(8.8)$ & $31(12)$ & 0.18 & $51(7.6)$ & $107(8.6)$ & $65(9.8)$ & 0.15 & 39 (12.6) & 57 (11.8) & $22(8.8)$ & 0.15 & $37(3.6)$ & 27 (1.5) & $38(4)$ & 0.61 \\
\hline
\end{tabular}

p-value from chi-squared test comparing differences in prevalence between Period-1 and Period-3. Fisher's exact test was used for counts $<5$ 
$\mathrm{NT}=$ non-typeable serotypes; $\mathrm{OTH}=$ all other serotypes 
Table 4. Comparison of prevalence of all pneumococci, PCV7 serotypes, additional PCV13 serotypes and non-PCV13 serotypes in HIV-uninfected and HIV-infected children and adults in 2013

\begin{tabular}{|r|l|l|l|l|l|}
\hline Age group & $\begin{array}{l}\text { Total } \\
\mathbf{N}\end{array}$ & $\begin{array}{l}\text { Overall } \\
\mathbf{n}(\mathbf{\%})\end{array}$ & $\begin{array}{l}\text { PCV7 } \\
\mathbf{n}(\mathbf{\%})\end{array}$ & $\begin{array}{l}\text { add PCV13 } \\
\mathbf{n}(\mathbf{\%})\end{array}$ & $\begin{array}{l}\text { Non PCV13 } \\
\text { n (\%) }\end{array}$ \\
\hline $\begin{array}{r}\text { Children } \mathbf{1 2} \text { years self- } \\
\text { reporting }\end{array}$ & & & & & \\
\hline HIV-uninfected & 488 & $290(59.4)$ & $61(12.5)$ & $27(5.5)$ & $205(42.0)$ \\
\hline HIV-infected & 15 & $10(66.7)$ & $2(13.3)$ & $2(13.3)$ & $6(40.0)$ \\
\hline p-value & & 0.79 & 0.92 & 0.20 & 0.88 \\
\hline $\begin{array}{r}\text { Adults >12 years self- } \\
\text { reporting }\end{array}$ & & & & & \\
\hline HIV-uninfected & 585 & $60(10.3)$ & $4(0.7)$ & $4(0.7)$ & $52(8.9)$ \\
\hline HIV-infected & 156 & $14(9.0)$ & $3(1.9)$ & $1(0.6)$ & $10(6.4)$ \\
\hline p-value & & 0.64 & 0.16 & 0.95 & 0.32 \\
\hline Adults >18 years tested & & & & & \\
\hline HIV-uninfected & 364 & $28(7.7)$ & 0 & $3(0.8)$ & $26(7.1)$ \\
\hline HIV-infected & 92 & $10(10.9)$ & $1(1.1)$ & 0 & $9(9.9)$ \\
\hline p-value & & 0.32 & - & - & 0.40 \\
\hline & & & & & \\
\hline $\begin{array}{r}\text { Adults >18 years self- } \\
\text { reporting }\end{array}$ & & & & & \\
\hline HIV-uninfected & 514 & $49(9.5)$ & $2(0.4)$ & $6(1.2)$ & $44(8.6)$ \\
\hline HIV-infected & 157 & $13(8.3)$ & $4(2.5)$ & $4(2.5)$ & $10(6.4)$ \\
\hline p-value & & 0.64 & 0.01 & 0.21 & 0.38 \\
\hline
\end{tabular}

Note that some individuals carried both vaccine and non-vaccine serotypes. 

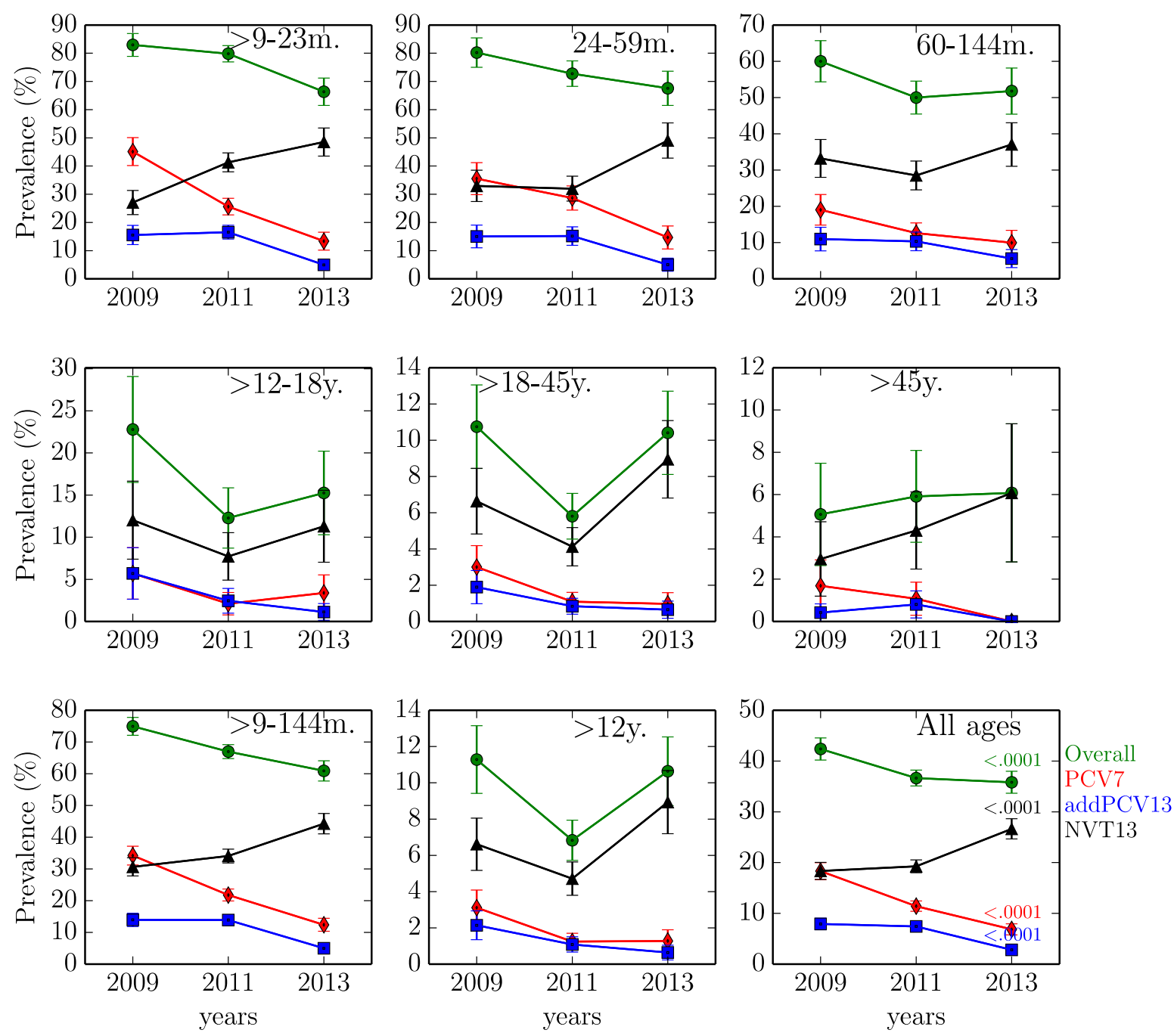

Figure 1. Prevalence of pneumococcal colonization in children and adults in a rural South African setting.

Footnote: The p-values in the panel for all ages represent the difference in prevalence in 2009 and 2013. 